\title{
Effects of mountain uplift on autumn rainfall over Southwest China
}

\author{
Qi Wang ${ }^{1}$, Jian $\operatorname{Liu}^{1,2,3}$, and Mi Yan ${ }^{1,2, *}$ \\ ${ }^{1}$ Key Laboratory for Virtual Geographic Environment of Ministry of Education/State Key Laboratory of Geographical \\ Evolution of Jiangsu Provincial Cultivation Base/School of Geography Science, Jiangsu Center for Collaborative Innovation in \\ Geographical Information Resource Development and Application, Nanjing Normal University, Nanjing, China \\ ${ }^{2}$ Open Studio for the Simulation of Ocean-Climate-Isotope, Pilot National Laboratory for Marine Science and Technology, \\ Qingdao, China \\ ${ }^{3}$ Jiangsu Provincial Key Laboratory for Numerical Simulation of Large Scale Complex Systems/School of Mathematical Science, \\ Nanjing Normal University, Nanjing, China
}

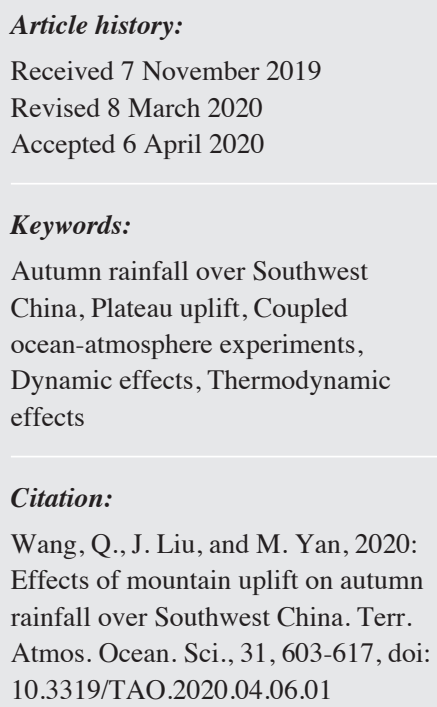

Citation:

Wang, Q., J. Liu, and M. Yan, 2020: Effects of mountain uplift on autumn rainfall over Southwest China. Terr. Atmos. Ocean. Sci., 31, 603-617, doi: 10.3319/TAO.2020.04.06.01

\begin{abstract}
The autumn rainfall over Southwest China is important for its agricultural and social effects. Studying the mechanism of its formation helps to improve its future prediction. A set of experiments, including eight stages of mountain uplift, is used to analyze the role of mountain uplift in the formation and development of autumn rainfall over Southwest China. The results show that the mountain uplift, especially the Tibetan Plateau is an essential factor in the formation and development of the autumn rainfall over Southwest China. The amount of the rainfall increases gradually with the mountain uplift. Being the transition season from summer to winter, the rainfall in autumn is influenced by the mountain uplift through dynamic and thermodynamic mechanisms in a different way from that in summer and/or in winter. Dynamically, with the Tibetan Plateau uplift, the upstream westerly is split into two branches, and the southern branch gets enhanced gradually and brings more water vapor from Arabian Sea and Bay of Bengal into the Southwest China region (the summer mode). Meanwhile, the East Asian trough is also strengthened, with the strengthened meridional circulation over mid-high latitudes, which favors the cold air from the north flowing into Southwest China (the winter mode) to converge with the warm humid air from the south (summer mode), resulting in the phenomenon of autumn rainfall over Southwest China. From the thermodynamic perspective, the surface heat source increases over the western part while decreases over the east part with Tibetan Plateau uplift, which promotes the ascending air flow over this area, and plays positive feedback on the increased autumn rainfall.
\end{abstract}

\section{INTRODUCTION}

In most areas of China, the rainy season ends in preautumn, but there is continuous, prolonged and wide-influenced rainfall in September or even in October over Southwest China, including those areas of Weishui River Basin, Hanshui River Basin, east Sichuan, and southeastern Sichuan (Bai and Dong 2004). It is known as autumn rainfall in Southwest China, which is the main feature of the autumn climate over Southwest China. The cold air that frequently flows southward in the autumn converges with the warm and humid airflow that persists over Southwest China, resulting

\footnotetext{
* Corresponding author

E-mail:myan@njnu.edu.cn
}

in long-term overcast and rainy weather associated with increased frontal activity (Sun et al. 2013). The continuous and frequent autumn rainfall over Southwest China occurs primarily from late August to early November, especially in September, coinciding with the harvest season there, which leads to crop yield reduction or loss of harvest, negatively impacting people's productivity and lives. Therefore, autumn precipitation over Southwest China has always been an important topic in climate research of this region.

As early as the mid-20th century, Gao (1958) and Gao and Guo (1958) identified the phenomenon of autumn rainfall over Southwest China. Those areas where the precipitation amounts or precipitation days in September or October 
were more than those in the months before and after were defined as the autumn rainfall region. In recent decades, numerous efforts have been made to explore the spatio-temporal characteristics and the physical mechanism of autumn rainfall over Southwest China (Feng and Guo 1983; Xu and Lin 1994; Bai and Dong 2004; Sun et al. 2010, 2013; Luo et al. 2013; Yu et al. 2013; Jiang et al. 2014; Wang et al. 2015a; Xu et al. 2017). It has been found that the autumn rainfall over Southwest China has obvious inter-annual and inter-decadal variation, and the Western Pacific Subtropical High (WPSH), the Indo-Burma trough and the Lakes Baikal-Balkhash trough were the main weather systems affecting this climatic feature. The well-developed Baikal trough and India-Burma trough and the strengthened WPSH would be favorable for more rainfall over Southwest China in autumn. Some studies suggested that the internal variabilities (such as sea surface temperature, SST) have great effects on autumn rainfall over Southwest China. For example, Liu and Yuan (2006a, b) and Liu et al. (2015a) found that there is a significantly positive correlation between Indian Ocean Dipole (IOD) and autumn rainfall over Southwest China. Zhang et al. (2013) showed that the warm pool El Niño was a principal factor of the strong autumn drought in Southwest China during 2009. And some investigators studied the effects of Pacific SST (Wang et al. 2015b, c) on this climate features. Zhao et al. (2016) found that the autumn rainfall over Southwest China would change from enhanced to suppressed when the main MJO (Madden-Julian Oscillation) convective body propagating from west to east. Some researchers focus on the changes and the associated atmospheric circulation of the autumn precipitation in a specific year (Bao et al. 2003; Zhang et al. 2011; Cai et al. 2012, 2013; Li et al. 2012; Liu et al. 2012; Chen et al. 2014; Wang et al. 2018). Most studies have revealed the impacts of climatic changes on autumn rainfall over Southwest China, but how this phenomenon develops and what causes it in the first place still need further investigations.

The Tibetan Plateau is the highest and steepest plateau over the world. This dramatic geographical feature has a significant impact on the atmospheric circulation system and climate conditions of the plateau itself, its neighboring regions, and even the entire globe via dynamic and thermodynamic effects (Ruddiman and Kutzbach 1991; Kutzbach et al. 1993; Li and Fang 1999; Liu 1999; Liu et al. 2001; Fan and Cheng 2003; Wang et al. 2013; Zhang et al. 2015; Yu et al. 2018). Up to now, many researchers have studied and discussed this significant topographical element. Liu (1999), Liu and Yin (2002), and Liu et al. (2013, 2015b), for example, carried out a series of studies on the impact of the Tibetan Plateau uplifting. Their results indicated that the plateau uplift could promote the formation of arid over Central Asia and North Africa, and had a strengthening effect on the South Asian monsoon. Thus, although the plateau uplift would enhance the monsoon precipitation, it could reduce the global precipitation. It was also found that the uplift of Tibetan Plateau could affect Indian summer monsoon, South Asia monsoon and East Asia monsoon and further affect the precipitation over these regions and the relative regions (An et al. 2001; Abe et al. 2003; Song et al. 2010; Zhang et al. 2012; Tang et al. 2013). Jiang et al. (2008) pointed out that the East Asia summer monsoon system similar to that of the present initially appeared when the altitude was $60 \%$ of the present height. Kitoh $(2004,2007)$ also found that there was a drastic change in the East Asian circulation with the threshold value at the $60 \%$ mountain height and the precipitation area would move inland of the Asian continent with mountain uplift in summer. Moreover, there was a critical height [e.g., about 1500 - $2000 \mathrm{~m}$ in summer (Zhang and Qian 1999), 40\% of the TP height (Abe et al. 2003, 2005), $50 \%$ of the modern TP height (Chen et al. 1999)] of the mountain uplift and the atmospheric circulation and precipitation over the vicinities of the plateau changed differently before and after this threshold. Liang et al. (2005) found that the uplift of Tibetan Plateau would lead to an increase in precipitation during the first rainy season over South China and a decrease in summer precipitation over South Asia. In addition, plateau uplift also would result in changes of the annual mean precipitation, the seasonal mean precipitation, the atmospheric circulation, and the sea surface temperature both over the vicinity of the plateau and over the remote areas (Lee et al. 2015).

At present, researches on the Tibetan Plateau uplift have primarily focused on its effects on the atmospheric circulation and the related climate changes in summer and winter over the vicinities of the plateau. Few has been done about the climate in transient seasons, particularly in autumn. Some studies mentioned the effects of the presence of the Tibetan Plateau on climatic changes in autumn, e.g., Chen et al. (2001) suggested that the surface heat source over eastern part of the plateau had a significant negative correlation with the autumn rainfall over Southwest China. The surface heat source anomalies over the eastern portion of the plateau would influence the amount of autumn rainfall over Southwest China through the $500 \mathrm{hPa}$ atmospheric circulation. Several previous studies also investigated the relationship between plateau summer monsoon and autumn rainfall over Southwest China (Tang 1993) and revealed the interaction between the terrain to the disaster rainstorm over Southwest China in September 2011 (Liu et al. 2013). They did not, however, explore the role of plateau uplift in the formation of the autumn rainfall over Southwest China. What role does Tibetan Plateau uplift play in the formation of autumn rainfall over Southwest China? Is Tibetan Plateau uplift an important cause of the evolution of autumn precipitation over this region? These questions remain to be answered.

This paper will investigate the autumn rainfall changes in different stages of mountain uplift, with a set of numerical experiments, and discuss the effect of plateau uplift on 
autumn rainfall over Southwest China from both dynamics and thermodynamics perspectives. The data and methods used in this study are introduced in section 2. The simulated results are validated in section 3 . The results and the dynamic and thermodynamic effects of the mountain uplift are discussed in section 4 . The conclusions and discussions are given in section 5 .

\section{DATA AND METHODS}

The data used in this paper includes both observation data and model simulations. The September mean land precipitation data provided by NOAA (National Oceanic and Atmospheric Administration) (Chen et al. 2002) is used as observation. The spatial resolution is $0.5^{\circ}$ (latitude) $\times 0.5^{\circ}$ (longitude), and the period is from 1972 to 2011 . The zonal and meridional wind, vertical velocity and specific humidity from NCEP/NCAR Reanalysis 1 (Kalnay et al. 1996) are also used as the observed circulation and moisture transport. The spatial resolution is $2.5^{\circ}$ (latitude) $\times 2.5^{\circ}$ (longitude) and the period is from 1961 to 2000 .

The simulation data are the orography sensitivity experiments derived from the ocean-atmosphere coupled model conducted by the Japan Meteorological Research Institute (MRI-CGCM) (Kitoh 2007), with a spatial resolution of approximately $2.8^{\circ} \times 2.8^{\circ}$. There are 8 runs with global mountain uplift of M0 (no mountain), M2, M4, M6, M8, M10 (with modern height), M12, M14, representing the mountain heights of $0,20,40,60,80,100,120$, and $140 \%$ of the current mountain height, respectively. M10 was the control run, with a terrain height equal to the modern states, as well as realistic land-sea distribution and topography. M0 was the no mountain run, although it maintained the same land-sea distribution as the control. In this study, M0 was selected as the reference run. All the eight experiments used the same initial conditions and only global mountain heights were uniformly varied, and all were integrated for 50 years. In order to prevent errors introduced by a climate drift, the data only for the last 40 years were used in this study (Lee et al. 2015).

The onset of the autumn rainfall in Southwest China is in September following the southward retreating of the plateau monsoon (Tang 1993), therefore we use September rainfall to represent the autumn rainfall phenomenon in Southwest China. Currently, there is no clear definition of the regions of autumn rainfall over Southwest China. Generally, Southern Shaanxi (mainly the Weihe River Basin and Hanshui River Basin), Southern Gansu, Sichuan, Chongqing, Guizhou, and Yunnan are considered to comprise Southwest China (Luo et al. 2013). We define the regions of autumn rainfall over Southwest China by referring to the indicators established by $\mathrm{He}$ (1984) and Bai and Dong (2004), which define the research area as $25-35^{\circ} \mathrm{N}$ and 100 $-110^{\circ} \mathrm{E}$

\section{MODEL VALIDATION}

To verify the reliability of the model simulations, we compare the observation data with the control run (M10). The spatial distribution of observed September mean precipitation (Fig. 1a) shows that there is a relatively prominent autumn rain phenomenon over Southwest China, where the rainfall is more than that over other parts of China. The simulated September rainfall distribution in the control run (M10) (Fig. 1b) is similar with the observed one, except that the rainfall is overestimated over Tibetan Plateau, northwest part of Southwest China and Indian subcontinent (Fig. 1c). It is noteworthy that the excessive precipitation center in the Tibetan Plateau is a common problem in all current global coupled ocean-atmosphere general circulation models $(\mathrm{Su}$ et al. 2013). The spatial correlation coefficient between the observation and the simulation over Southwest China is 0.89 , passed a 0.05 statistical significance test, indicating that the model can reasonably represent the spatial characteristics of autumn rainfall over Southwest China.

The comparisons between the simulated and the observed circulations (Figs. 1d - 1) show that the model can well reproduce the main circulation patterns, including the two branches of low-level westerlies and the West Pacific subtropical high circulation (Figs. 1d - e), the ascending flows over mid-low latitudes and southwest China (Figs. 1g - h), and the meridional circulations (Figs. $1 \mathrm{j}-\mathrm{k}$ ). However, the model tends to overestimate the vertical velocity over Southwest China and Indian subcontinent (Fig. 1i), which leads to the overestimated precipitation over these regions (Fig. 1c). The meridional circulation is also overestimated (Fig. 11), whereas the southern branch of the westerlies is underestimated (Fig. 1f). Regarding the underestimated southern branch of the westerlies, the low-level moisture transport from Arabian Sea and Bay of Bengal is underestimated while the moisture transport from west Pacific Ocean is overestimated (Figs. 1m-o). Although it is overestimated or underestimated, the basic circulation patterns and systems are well depicted in the model.

In addition, this set of experiments has been used to investigate the effects of mountain uplift on the Asian monsoon and global monsoon evolution, including the JJA and DJF precipitation and circulation, and also the ENSO variability (Kitoh 2004, 2007; Kitoh et al. 2010; Lee et al. 2015).

Therefore, despite the above-mentioned systematic biases, this set of experiments can be used to help understanding the climate responses to the mountain uplift.

\section{RESULTS}

\subsection{Changes of Autumn Rainfall Over Southwest China}

Figure 2 shows the spatial distribution of September mean precipitation in the 8 mountain uplift experiments. It can be seen that in the non-mountain stage (M0) and the 
(a) NOAA

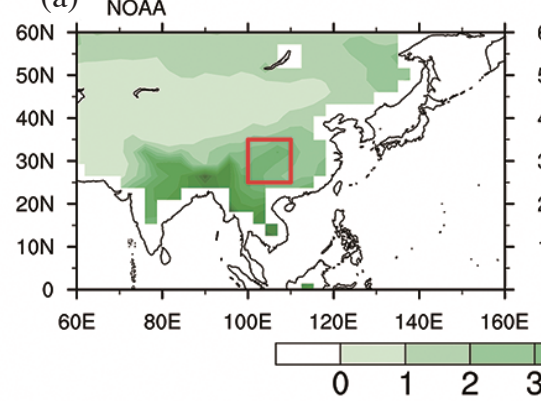

(b) MRI-CGCM(CTRL)

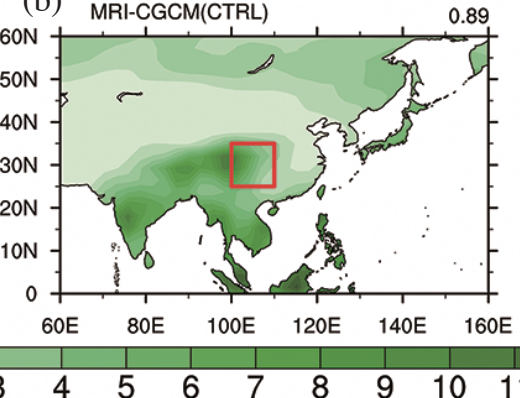

(c) difference

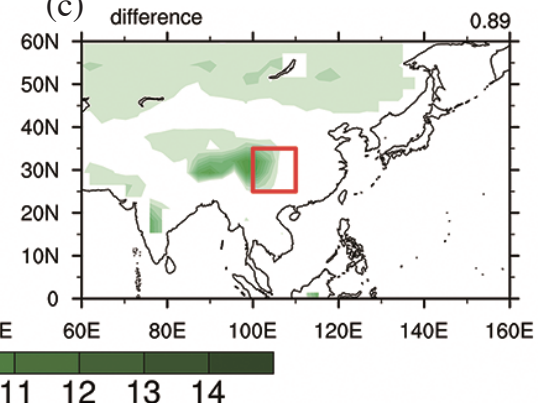

(d) NCEP

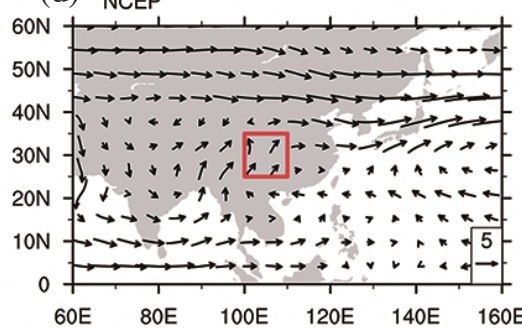

(g) NCEP

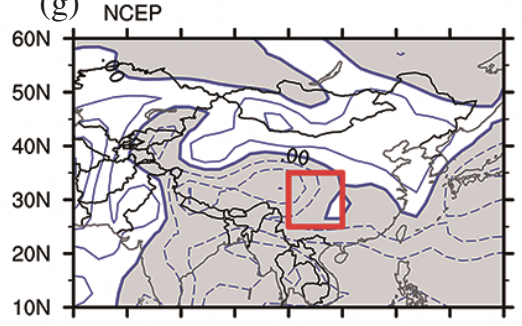

GOE 70E 80 E 9OE 100 E 110 E 120 E 130 E 140 E

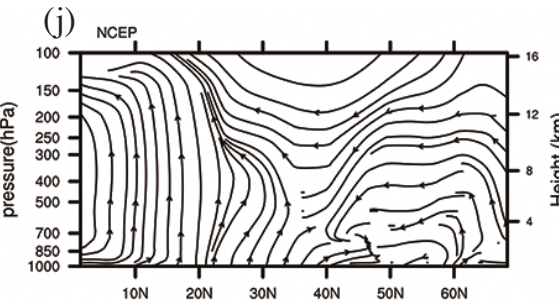

(m) NCEP

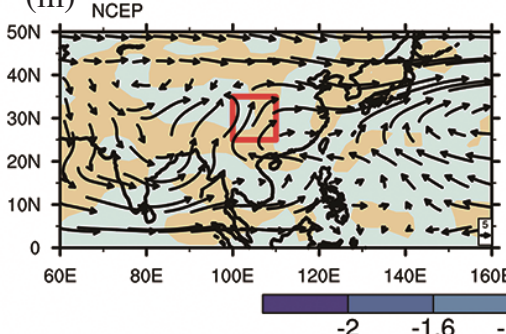

(e) MRI_CGCM(CTRL)

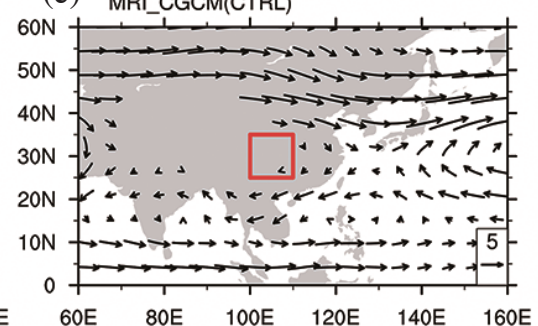

(h) MRI CGCM

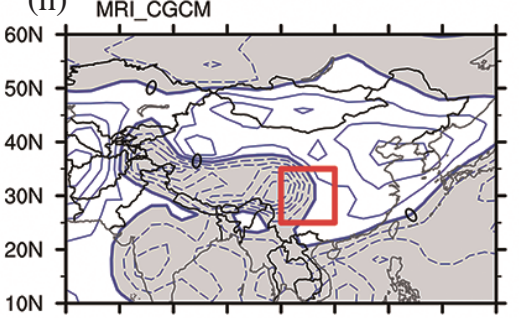

GOE 70E 80 E 9OE 100 E 110 E 120 E 130 E 140 E

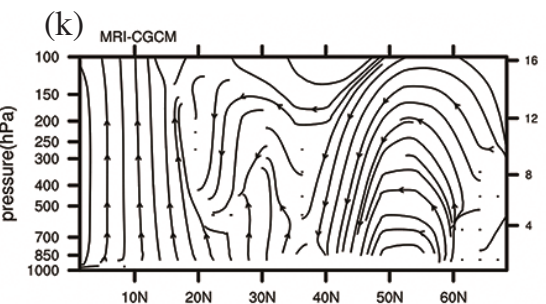

(f) difference

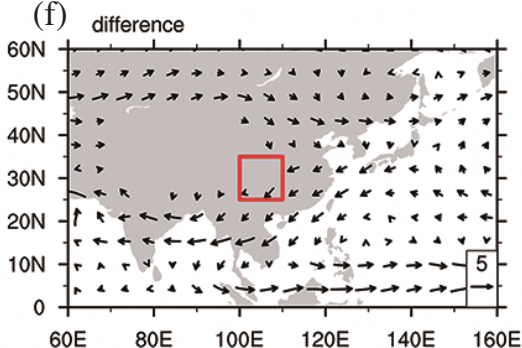

(i) difference

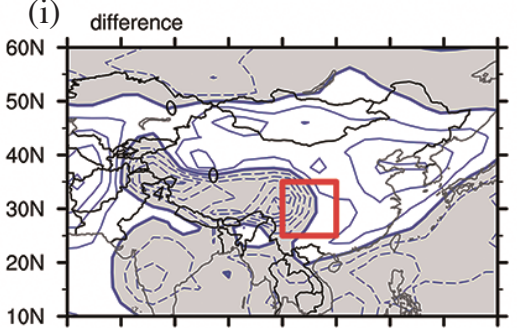

GOE 70E 80 E 9OE 100 E 110 E 120 E 130 E 140 E

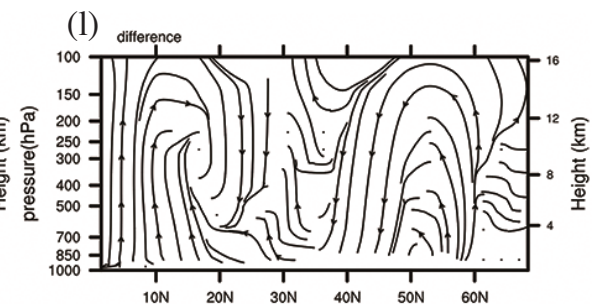

(n) MRI_CGCM

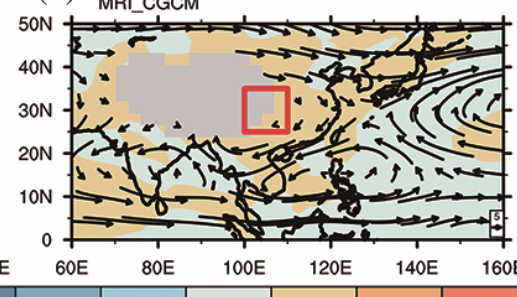

(O) difference

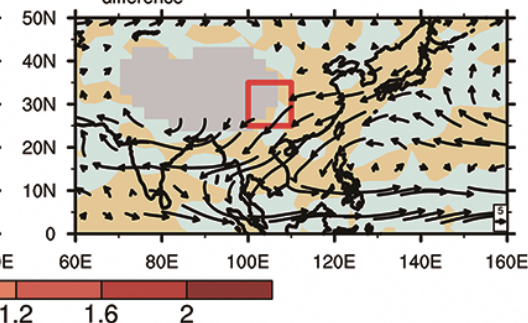

Fig. 1. Spatial pattern of September mean precipitation rate $\left(\mathrm{mm} \mathrm{day}^{-1}\right), 700 \mathrm{hPa}$ wind $\left(\mathrm{m} \mathrm{s}^{-1}\right), 500 \mathrm{hPa}$ omega $\left(\mathrm{Pa} \mathrm{s}^{-1}\right)$, latitude-pressure cross section of meridional circulation along $100-110^{\circ} \mathrm{E}, 700 \mathrm{hPa}$ moisture flux $\left(\mathrm{kg} \mathrm{m}^{-1} \mathrm{~s}^{-1}\right)$ and its divergence $\left(\mathrm{kg} \mathrm{m}^{-2} \mathrm{~s}^{-1}\right)$ derived from (a) NOAA, (b) MRI-CGCM, (c) difference between MRI-CGCM and NOAA. The red boxes enclose the region of Southwest China. The number in the upper-right corner of the (b) is the pattern correlation coefficient between the control run (M10) and NOAA in red box. 
(a) MO

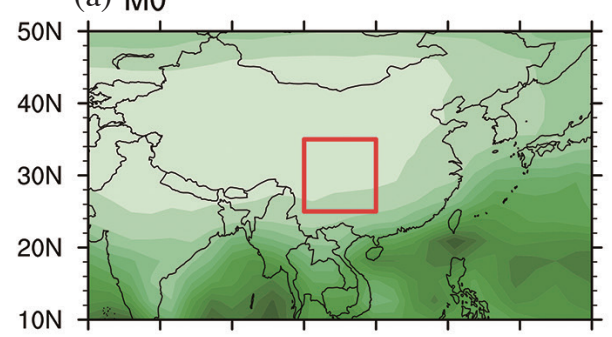

(c) M4

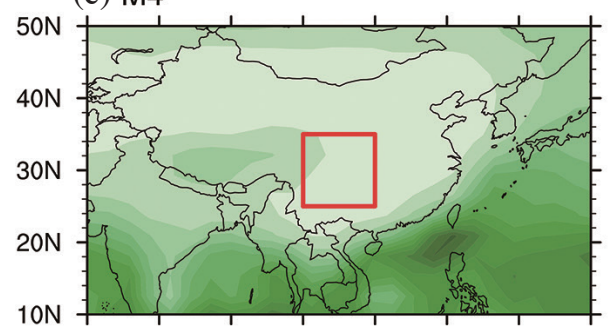

(e) $\mathrm{M} 8$

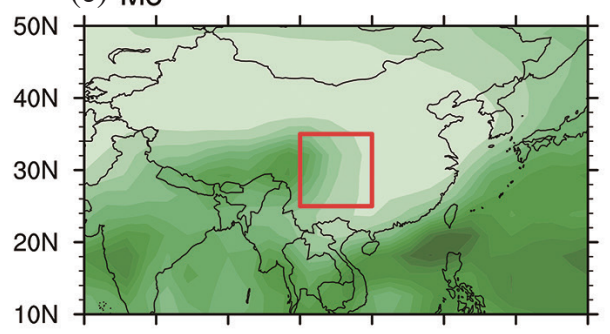

(g) M12

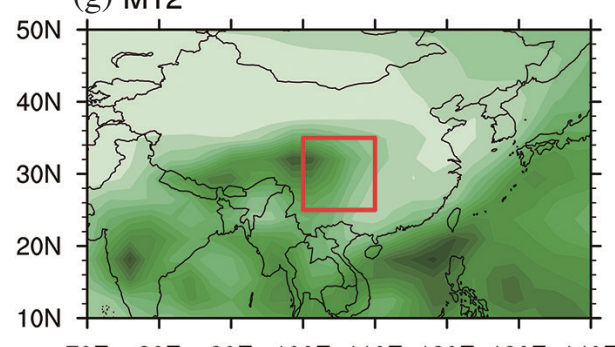

70E 80E 90E 100E 110E 120E 130E 140E 70E 80E 90E 100E 110E 120E 130E 140E (b) $\mathrm{M} 2$

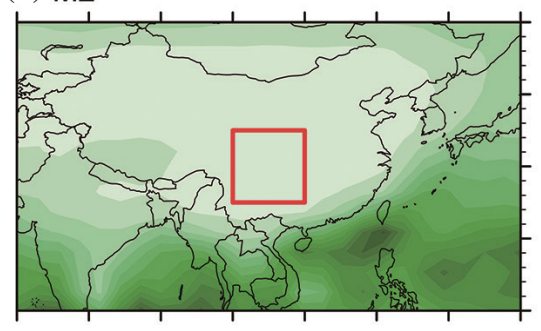

(d) $\mathrm{M} 6$

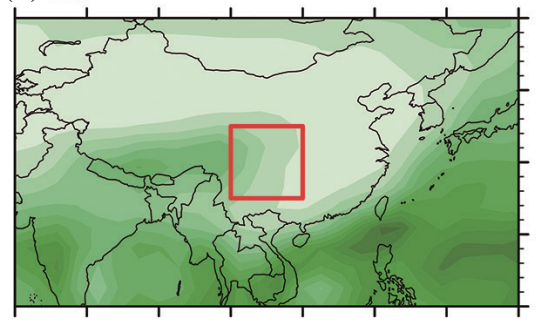

(f) $\mathrm{M} 10$

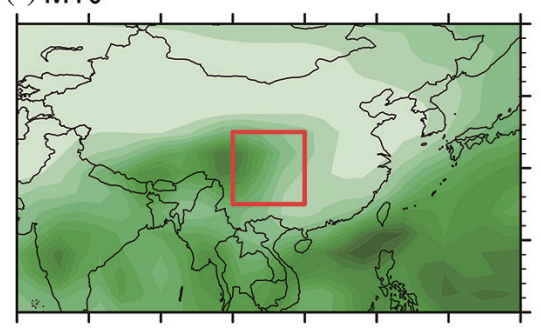

(h) M14

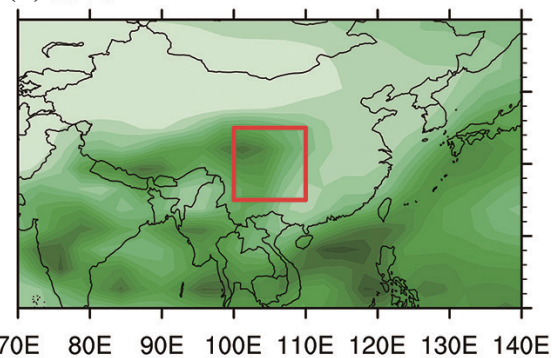

Fig. 2. Spatial pattern of September mean precipitation rate $\left(\mathrm{mm}^{-1} \mathrm{y}^{-1}\right)$ derived from 8 different stages of mountain uplift. 
early stage (M2) of the mountain uplift, the precipitation over China is characterized by a decreasing pattern from southeast to northwest, with no prominent autumn rainfall phenomenon over Southwest China. Although the precipitation increases over the western part of the Tibetan Plateau in the early stage (M2), it is decreased over the southeast China and the Southwest China. The precipitation over the western part of the Tibetan Plateau is increased gradually and propagates to the eastern part with the uplifting of the mountain. The phenomenon of autumn rainfall over Southwest China is present in and after M6, and becoming more and more prominent. During the uplift of the mountain, the autumn rainfall over Southwest China initially decreased by $0.503 \mathrm{~mm}$ day $^{-1}$, then gradually increased from 0.435 to $0.763 \mathrm{~mm}$ day $^{-1}$ (Fig. 3).

According to the above analysis, the mountain uplift would lead to the onset and evolution of the autumn rainfall over Southwest China. Autumn precipitation over Southwest China varies during different stages of the mountain uplift, demonstrating an overall trend of autumn rainfall over Southwest China gradually increasing with increasing mountain height.

\subsection{Dynamic Effects}

Autumn is a transition season from summer-type circulation to winter-type circulation. The northerly East Asian winter monsoon is taking place the southerly East Asian summer monsoon. In September, the Southwest China is located between the WPSH and the Iran High. The warm and humid air from South China Sea and Bay of Bengal brought by the southerly and southwesterly wind converges with the cold air from mid-high latitude brought by the westerly and northeasterly wind into the Southwest China and thus forms the typical autumn rainfall phenomenon (Fig. 4).

\subsubsection{Changes of Atmospheric Circulations}

In the no mountain stage, the Asia is dominated by westerly over mid-high latitudes while northeasterly to easterly over mid-low latitudes, the shifting latitude is $30^{\circ} \mathrm{N}$, with zonally distributed geopotential height at $500 \mathrm{hPa}$ (Fig. 5a). In the early stage of the mountain uplift (M2), the Southwest China is controlled by an anticyclone circulation anomaly and thus experiences the reduced precipitation (Fig. 5b). When the mountain is uplifted to the M4 stage (figure not shown), i.e., the height is $40 \%$ of its modern one, the high-pressure ridges over the area from Lakes Baikal and Balkhash to the mid-high latitudes of Eurasia shows up, along with a low pressure and cyclonic circulation anomaly over its downstream (the Korean Peninsula and Sea of Japan). The East Asian trough also appears, leading to the strengthened north-south pressure gradients and the corresponding meridional circulation, which is conducive to the southward movement of the cold air from mid-high latitudes. As the mountain continues uplifting to its present height (Figs. 5c, d), the anticyclonic and cyclonic circulation anomalies over the upstream and downstream of the Lake Baikal keep strengthening, accompanied by the deepening of the East Asian trough and the increasing north-south pressure gradients. Furthermore, during the early stage, a westerly wind anomaly is developed over the Arabian Peninsula. This westerly wind anomaly is gradually strengthening and stretching eastward with the mountain uplifting. The southern branch of the westerlies around the plateau gradually forms and strengthens in response to the mountain uplift. Additionally, as the mountain height rises over $60 \%$ of its current height, the anticyclonic circulation anomaly corresponding to the western Pacific subtropical high appears and gradually strengthens. The southwesterly winds over the west side of this anticyclone combined with the south branch

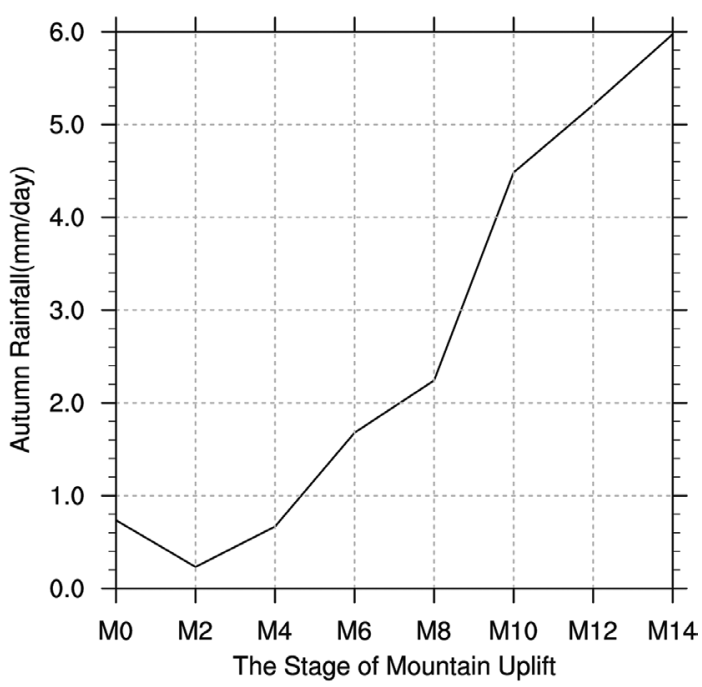

Fig. 3. Autumn precipitation rate $\left(\mathrm{mm} \mathrm{day}^{-1}\right)$ over Southwest China associated with different stages of mountain uplift. 


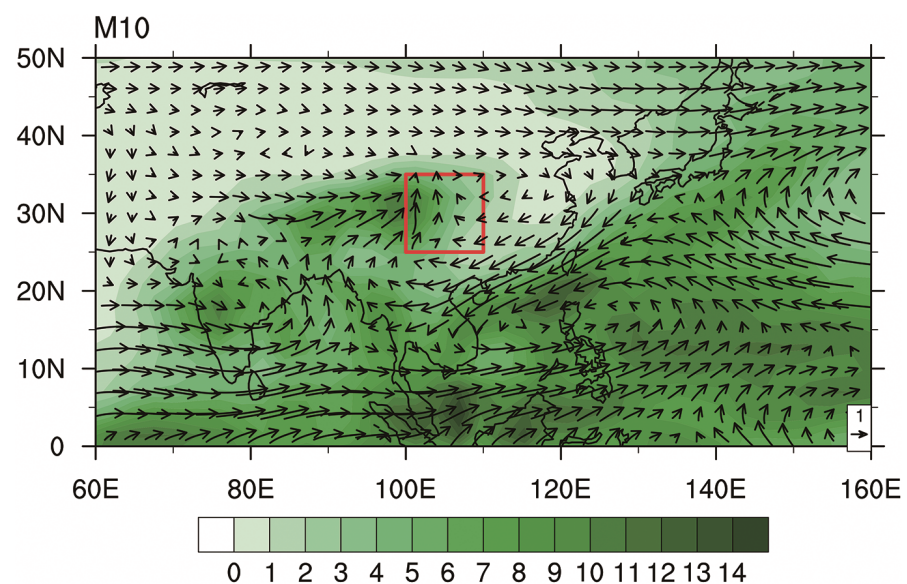

Fig. 4. Spatial pattern of September mean precipitation (shading; units: $\mathrm{mm}_{\text {day }}{ }^{-1}$ ) and integrated moisture flux (vector; units: $100 \mathrm{~kg} \mathrm{~m} \mathrm{~m}^{-1} \mathrm{~s}^{-1}$ ) of $\mathrm{M} 10$.

(a) $\mathrm{MO}$

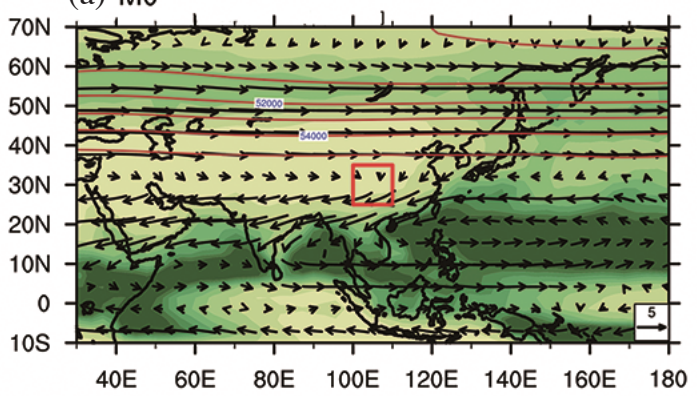

(b) M2-M0

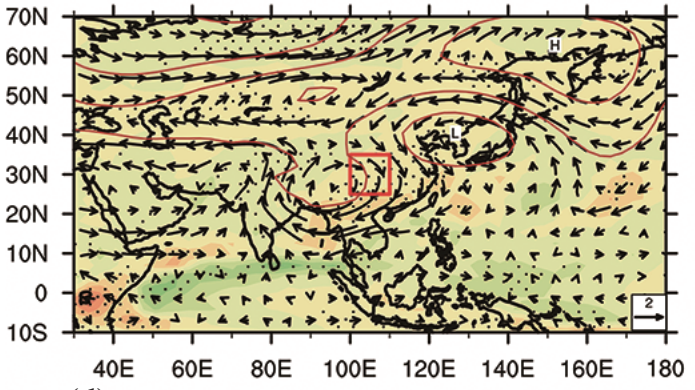

(d) M10-M0

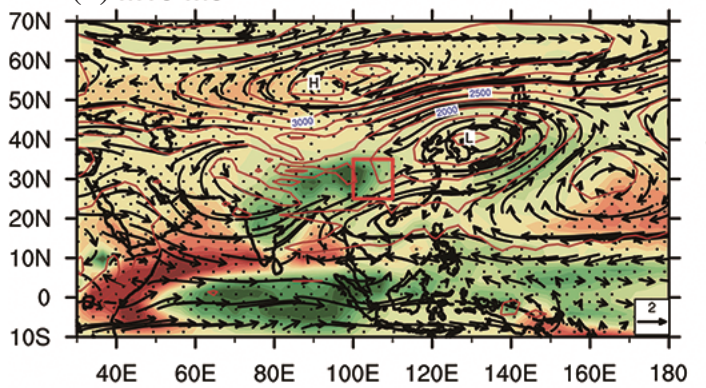

(c) $\mathrm{M} 6-\mathrm{M0}$

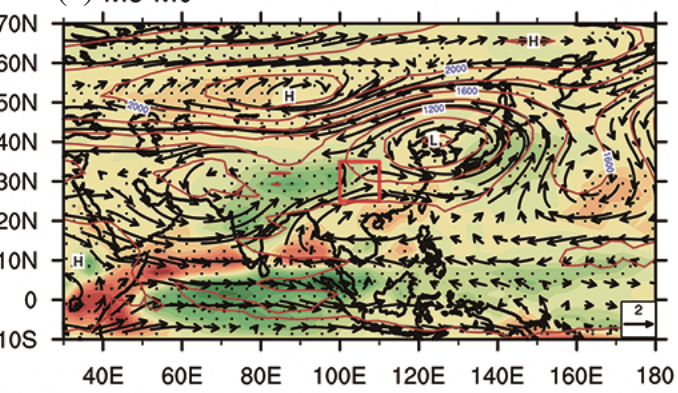

(e) M14-M0

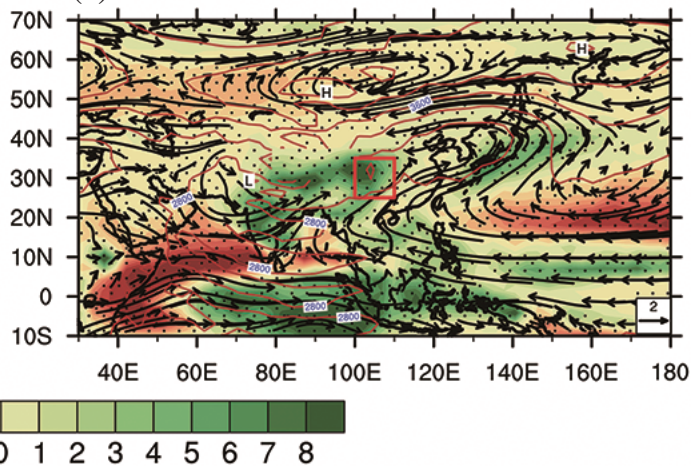

Fig. 5. (a) Spatial pattern of September mean $700 \mathrm{hPa}$ wind (vector; units: $\mathrm{m} \mathrm{s}^{-1}$ ), $500 \mathrm{hPa}$ geopotential height (contour; units: Pa), and precipitation (shading; units: $\mathrm{mm} \mathrm{day}^{-1}$ ) of M0 and (b) - (h) differences of $700 \mathrm{hPa}$ wind, $500 \mathrm{hPa}$ geopotential height, and precipitation between M2, M6, M10, M14, and M0, respectively. Areas with confidence levels greater than $95 \%$ are dotted for precipitation. 
of westerly flow around the southern side of the plateau, bringing warm and humid airflow into Southwest China, and thus benefiting the precipitation over this region.

When the mountain keep uplifting over its current height (Fig. 5e), the cyclonic circulation anomaly over the Sea of Japan gradually weakens and disappears, while the southern branch of westerlies around the plateau remains basically the same as it is during the M10 (current height) stage. The high-pressure ridges over the mid-high latitudes of the Northern Hemisphere, the East Asian trough and the western Pacific subtropical high continue to intensify, which benefit the continued increase of autumn rainfall over the Southwest China.

The global patterns of the circulation changes illustrate that the main causes of autumn rainfall over Southwest China are relatively from the local effects of uplift of Tibetan Plateau rather than from the remote effects of uplift of other mountains (not shown).

Above all, the dynamic effects of mountain uplift, especially the plateau uplift on the autumn rainfall over Southwest China are reflected in their influence on the high-pressure ridges over the mid-high latitudes of the Eurasian continent, the East Asian trough, the southern branch of westerlies around the Tibetan Plateau, and the western Pacific subtropical high.

\subsubsection{Changes of Water Vapor Transport}

The sufficient water vapor supply provides favorable conditions for the continuous precipitation. The climatology of the moisture flux and its divergence in September in the M0 stage (Fig. 6a) and the differences between those in the seven stages (M4, M8, M12 are not shown) and M0 (Figs. 6b-e) show that, with the uplifting of the Tibetan plateau, the northeast transportation of the moisture flux over Southwest China increases gradually. The warm and humid air from the ocean, especially from the Arabian Sea and Western Pacific, keep transporting to Southwest China, meanwhile, the moisture flux convergence becomes stronger over this region. In the non-mountain stage (M0), the southern part of Southwest China is dominated by westerly moisture flux with significant water vapor divergence.

\section{(a) Mo}

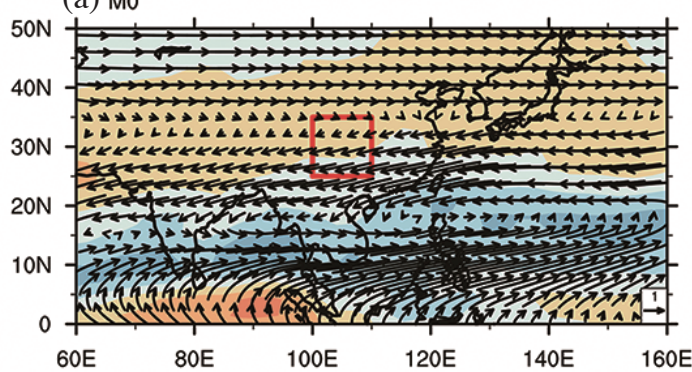

(b) M2 - MO

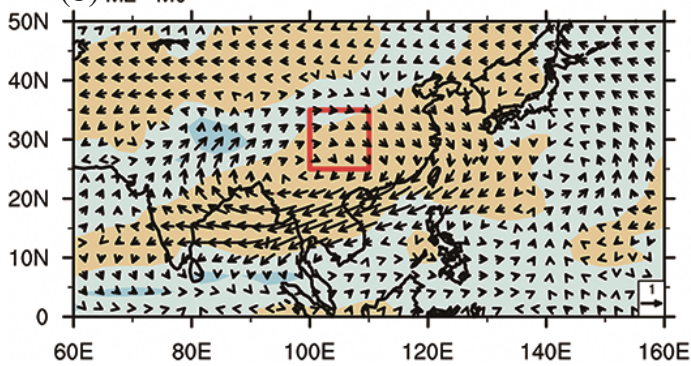

(d) $\mathrm{M} 10$ - M0

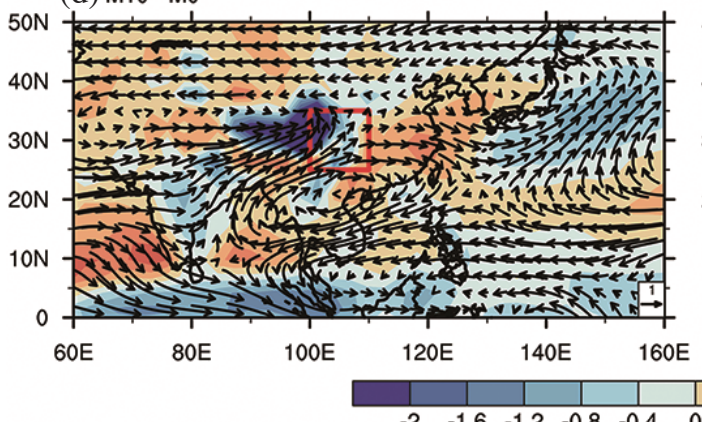

(c) M6 - MO

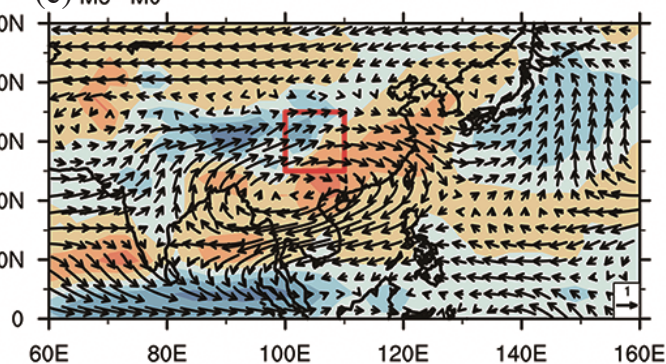

(e) $\mathrm{M} 14$ - MO

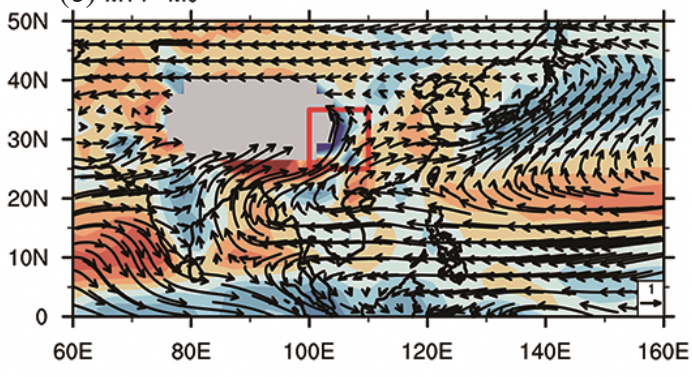

$\begin{array}{lllllllllll}-2 & -1.6 & -1.2 & -0.8 & -0.4 & 0 & 0.4 & 0.8 & 1.2 & 1.6 & 2\end{array}$

Fig. 6. The same as Fig. 5, but for the moisture flux (vector; units: $100 \mathrm{~kg} \mathrm{~m}^{-1} \mathrm{~s}^{-1}$ ) and its divergence (color; units: $\left.10^{-6} \mathrm{~kg} \mathrm{~m}^{-2} \mathrm{~s}^{-1}\right)($ vertically integrated from surface to $500 \mathrm{hPa}$ ). 
Combined with the anticyclonic circulation in this stage over Southwest China (Fig. 5a), it can be deduced that this is not conducive to the formation of precipitation. Therefore, the autumn rainfall over Southwest China is relatively low during the non-mountain stage. In the M2 stage (the early stage of uplift), there is strong west and northwest moisture flux and an anomalous divergence of water vapor over Southwest China, whereas this region is still affected by an anticyclonic circulation (Fig. 5b). Therefore, there is still no obvious autumn rainfall phenomenon over Southwest China. The autumn rainfall over Southwest China during this stage is actually less than that during the non-mountain stage. From M4 to M10, the water vapor mainly comes from Arabian Sea and Bay of Bengal, with the enhanced southwesterly water vapor transporting and convergence, and thus a large amount of warm and humid water vapor into Southwest China. From M12 to M14, the water vapor comes not only from the Arabian Sea and Bay of Bengal, but also from the western Pacific Ocean through southeasterly circulation, and accompanies the increase of moisture flux convergence, the autumn rainfall over Southwest China continually increases.
To sum up, the warm and humid airflow from the Arabian Sea, Bay of Bengal and the mid-low latitudes of western Pacific begins to converge into Southwest China, and keeps strengthening with the mountain uplifting. Therefore, it helps to increase the amount of autumn rainfall over Southwest China.

It can also be found that with the mountain uplift, there keeps an anomalous anticyclone in the Indochina Peninsula helping providing the northeasterly moisture to converge into Southwest China (Figs. 5, 6). This anomalous anticyclone might be dynamically related to the downstream effects of westerly flowing around the Tibetan Plateau, as well as to the strengthened western Pacific subtropical high.

\subsubsection{Changes of Vertical Motion}

Overall, the average vertical velocity (omega) distribution (figure not shown) at $500 \mathrm{hPa}$ in September during the 8 stages of mountain uplift is consistent with the precipitation distribution. During the non-mountain stage, most areas of China are dominated by the descending motion (Fig. 7a). Therefore, the precipitation over most of China during the

(a) Mo

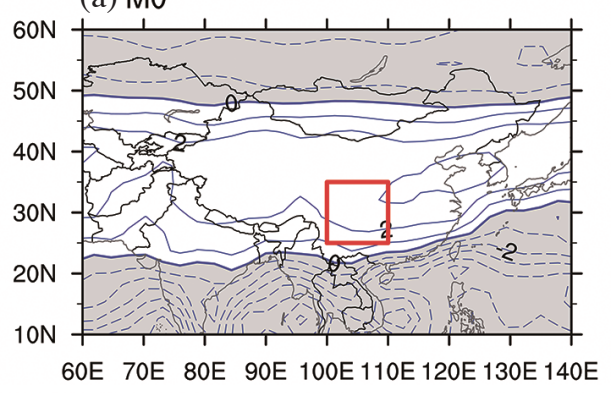

(b) $\mathrm{M} 2-\mathrm{MO}$

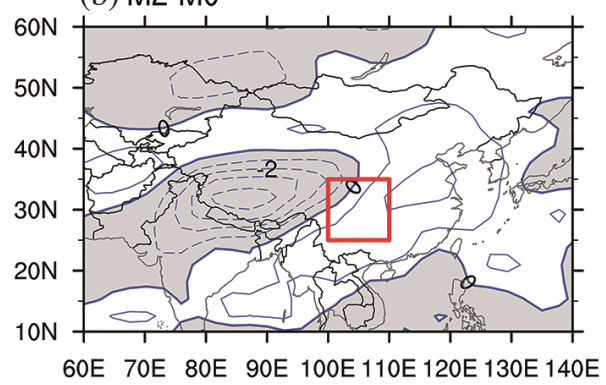

(d) M10-MO

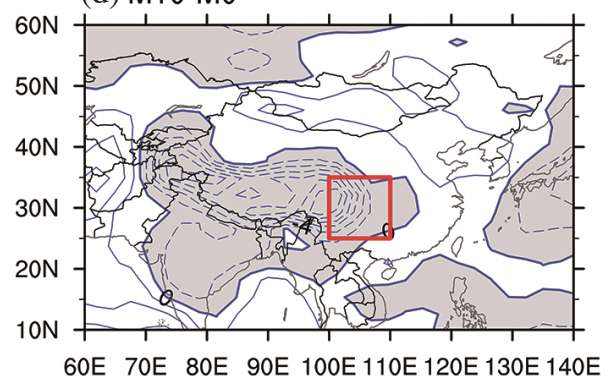

(c) M6-MO

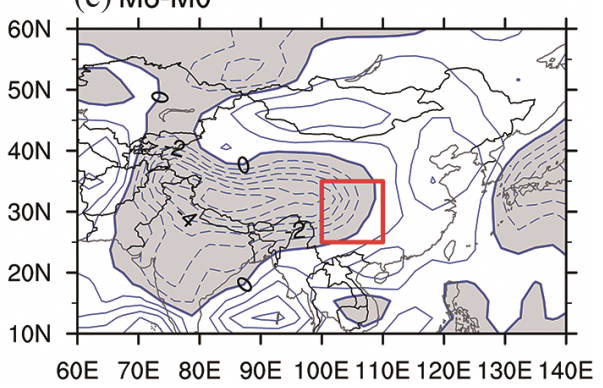

(e) M14-M0

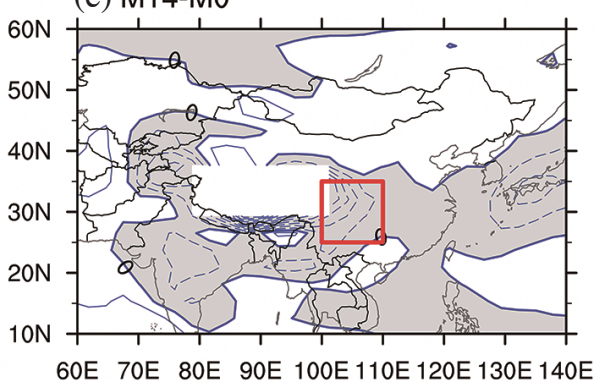

Fig. 7. The same as Fig. 5, but for $500 \mathrm{hPa}$ omega (units: $10^{-4} \mathrm{hPa} \mathrm{s}^{-1}$ ). The negative values are shaded. 
M0 stage is relatively low. As the elevation of the mountain increased, ascending motion over the Tibetan Plateau keeps strengthening, and the area where the ascending motion strengthened is gradually extending to the eastern part of China. Compared to the M0 stage, most areas of Southwest China during the early stage of the uplift (M2) are still affected by the descending motion (Fig. 7b), so the phenomenon of autumn rainfall over Southwest China is still not evident. From M6 to M14 (Figs. 7c - e), vertical air motion over Southwest China changes from descending to ascending, with ascending motion keeps strengthening. In response to these changes in vertical air motion, the amount of autumn rainfall over Southwest China increases from M6 to M14, corresponding to the results shown in Fig. 2. In addition, changes in autumn precipitation over Southwest China are not uniform across the area at some individual stages during the mountain uplift. For example, during the M8 stage, the western part of Southwest China is dominated by convergence and ascending air motion, while the eastern part is experiencing the opposite conditions. But combined with the variations of atmospheric circulation and water vapor transportation, there is also more autumn precipitation in Southwest China overall at the M8 stage than that at the M0 stage. In general, as the elevation of the mountain increased, the vertical motions of the atmosphere over Southwest China changes from divergent sinking-based to convergent rising-based. Correspondingly, the autumn rainfall over Southwest China exhibits an initial decreasing trend followed by a gradual increase trend.

\subsection{Thermodynamic Effects}

In addition to the dynamic effects of the mountain uplift, particularly the Tibetan Plateau uplifting on the atmosphere, it has thermodynamic effects through heating and cooling processes in different seasons. It is said that the thermodynamics effects of the Tibetan Plateau are the strongest in summer, with the surface sensible heating being prominent prior to the monsoon onset, and would significantly affect the transition of circulation patterns from winter season to summer season (Wang et al. 2008). Whereas the heating/ cooling processes in the transition season of autumn require clarification. In this study, we referred to the method of Li et al. (2016), using the sum of surface turbulent sensible heat flux and latent heat flux of soil evaporation as the surface heat source value. As shown in Fig. 8a, when there is no plateau, the surface heat source value over southeastern China is large and the surface heat source over the Tibetan Plateau region is relatively small. With the mountain uplifting, the heat source over the western part of the plateau region gradually increases, while the heat source over the eastern part of the plateau and the areas to its east is gradually decreasing. It can be seen that in September, the Tibetan Plateau, especially its western part, is still an atmospheric heat source center. There is a significant difference in the heating effects between the western and eastern parts of the plateau (Figs. 8b-e), which is consistent with the results of Ye and Gao (1979). Compared with the non-mountain stage, the surface heat source value over the western section of the plateau is found to increase with mountain uplifting, while that of the eastern section is decreasing. The surface heat source value over Southwest China decreases by $4.5 \mathrm{~W} \mathrm{~m}^{-2}$ in $\mathrm{M} 2$ and by $32.6 \mathrm{~W} \mathrm{~m}^{-2}$ in M14 comparing to M0, the decreasing trend is almost linear with mountain uplift. The higher the elevation, the greater the amplitude of the heat source increases or decreases.

In September, the mean meridional circulation over the region of $100-110^{\circ} \mathrm{E}$ (Fig. 9) shows that during the nonmountain stage (Fig. 9a) there are strong southerly winds and ascending air flow from the equator to $15^{\circ} \mathrm{N}$, while the region of Southwest China $\left(25-35^{\circ} \mathrm{N}\right)$ experiences strong northerly winds and descending motion. It can be seen from the anomalies maps (Figs. 9b - e) that, during the early stage of mountain uplift, Southwest China is still affected by the strong descending motion, and the northerly winds in the lower troposphere remain strong. At this time, the thermodynamic effect of the plateau has not yet appeared. When the plateau rises to $40 \%$ of its current height (figure not shown), the heat source effect over the western part of the plateau begins to form, and the ascending motion starts to appear over the area near $30^{\circ} \mathrm{N}$. As the altitude of the mountain increases, the heat source effect over the western part of the plateau is gradually strengthening, along with the increasing ascending motion over Southwest China. These conditions are readily benefiting the increase of precipitation over Southwest China.

In summer, the Tibetan Plateau serves as heat source to the atmosphere, and triggers South Asian High in upper troposphere, forms meridional plateau monsoon circulation, accompanied by a strengthened ascending flow of South Asian summer monsoon (Liu et al. 2007). With the mountain uplift, the heat source in September in west part increases (Fig. 8), which helps strengthening the ascending flow (Fig. 9) on one hand.

On the other hand, the cooling in the eastern part of the plateau and Southwest China might be caused by the increased rainfall. The increased rainfall along with the cooled surface can force a Matsuno-Gill pattern in the upper troposphere and an anomalous anticyclonic circulation in low-level to its south (Yang et al. 2007). That is to say, the abovementioned low-level anomalous anticyclonic circulation in Indochina Peninsula might also be related to the thermodynamic effect of the mountain uplift.

When combined with the distribution of autumn precipitation (Fig. 2), it can be seen that the thermodynamic effect of the Tibetan Plateau uplifting has a specific impact on the occurrence and development of autumn rainfall over Southwest China. The thermodynamic effects of mountain 
uplift might be a positive feedback to the increased rainfall.

\section{CONCLUSION AND DISCUSSION}

The effects of mountain uplift on the large-scale climate in boreal summer and winter, such as summer monsoon and winter monsoon, have been investigated in the previous studies (Liu and Yin 2002; Abe et al. 2003; Kitoh 2004; Jiang et al. 2008; Kitoh et al. 2010; Lee et al. 2015). However, little has been done on the effects of mountain uplift on the climate in transition seasons, especially in the autumn. In this study, the effects of mountain uplift on the phenomenon of autumn rainfall over Southwest China are analyzed using eight experiments conducted by the Japan Meteorological Research Institute with a coupled oceanatmosphere general circulation model (MRI-CGCM). It is found that the mountain uplift, mainly the Tibetan Plateau uplift, leads to the occurrence of autumn rainfall over Southwest China, and also influences the amount of the autumn precipitation. During the early stage of mountain uplift, the amount of autumn rainfall over Southwest China decreases slightly, but in general, the amount of autumn rainfall in this region gradually increases with the mountain uplift.

As suggested by Liu (1999), the Tibetan Plateau had significant impacts on the atmospheric circulations over mid-low latitudes through the dynamic and thermodynamic mechanisms. In the dynamic point of view, Kitoh et al. (2010) compared the effects of mountain uplift on the boreal summer circulation and the boreal winter circulation and found that both circulations were enhanced with the uplifting. The autumn is a transition season that the circulation changes from summer pattern to winter pattern. The dynamic mechanism of mountain uplift influencing the autumn rainfall shows a combination of summer mode and winter mode. The uplift of the plateau divides the westerly over Eurasia into two branches, the southwesterly on the southern branch (summer mode) is strengthened. Meanwhile, the East Asian trough (winter mode) and the western Pacific subtropical high (summer mode) are also strengthened. These favor the cold air from the northern part

(a) Mo

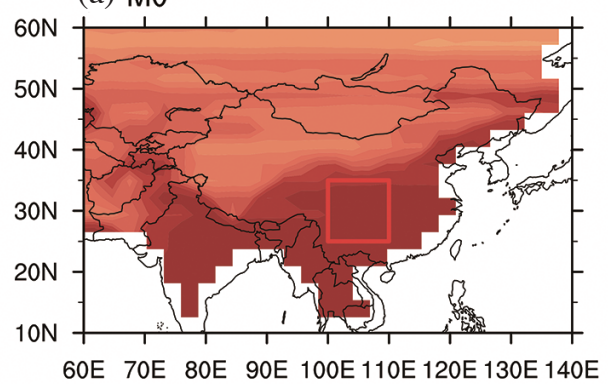

(b) M2-M0

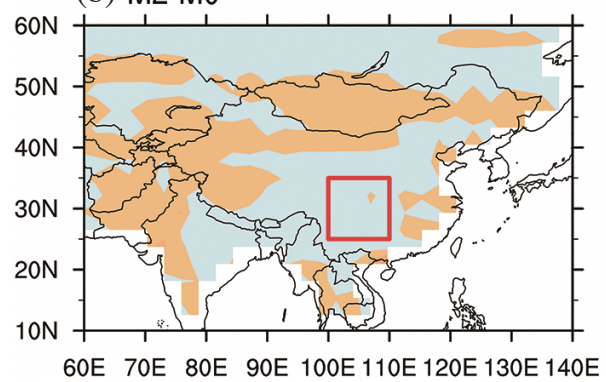

(d) M10-M0

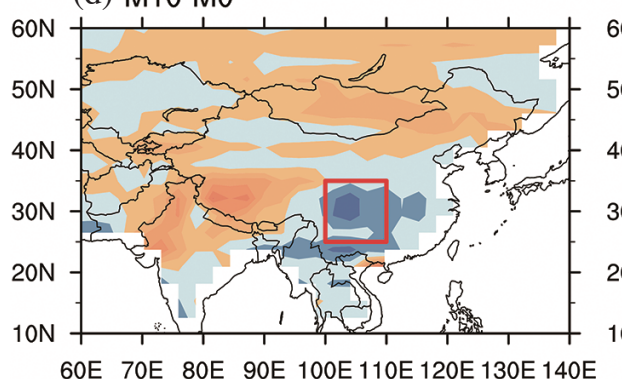

60 E 70E 80 E 90E 100E 110E 120E 130E 140E (c) M6-MO

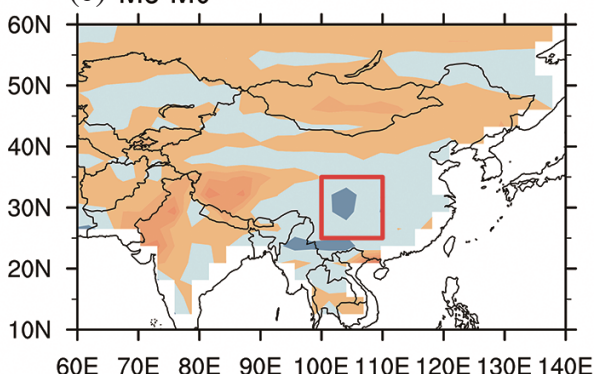

(e) M14-M0

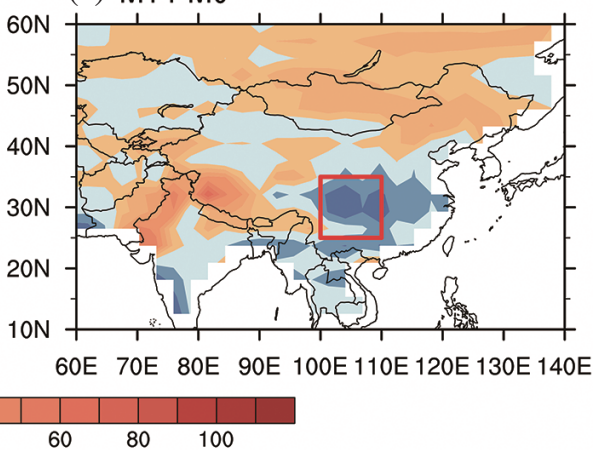

Fig. 8. The same as Fig. 5, but for surface heat source (units: $\mathrm{W} \mathrm{m}^{-2}$ ). 


\section{0-110E mean pressure-latitude}

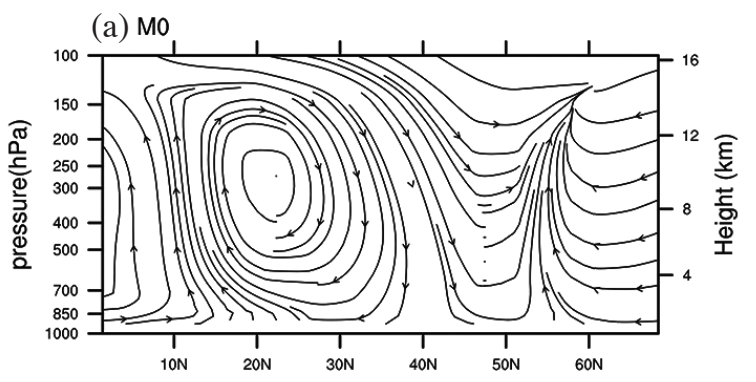

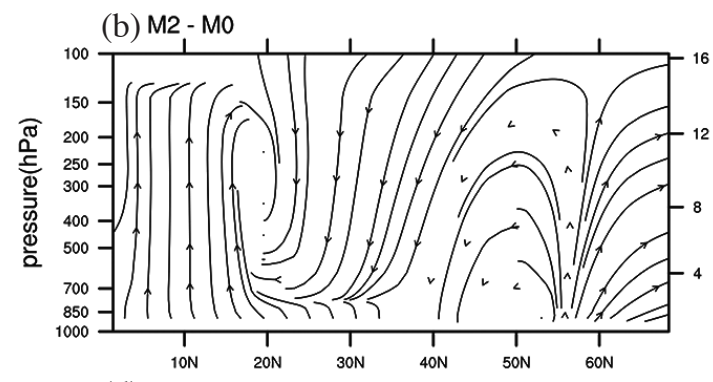

(d) M10 - M0

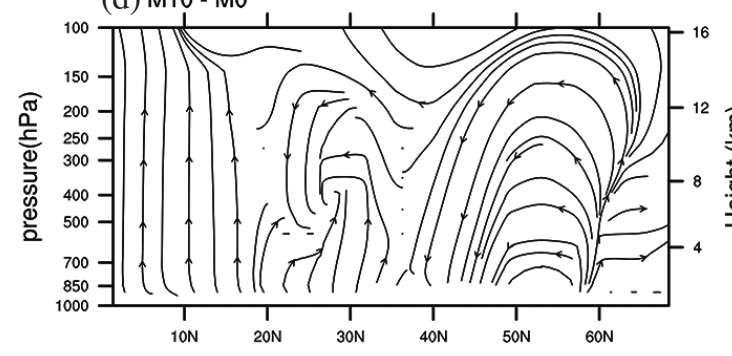

Fig. 9. The same as Fig. 5, but for latitude-pressure cross section of meridional circulation along $100-110^{\circ} \mathrm{E}$ in September. (winter mode) and the warm, humid air from the southern part (summer mode) converging into Southwest China and thus form the particular autumn rainfall.

From the thermodynamic perspective, the uplift of the Tibetan Plateau results in changes of the surface heat source value. Chen et al. (2001) found that the heat source over the eastern part of the plateau was negatively correlated with the autumn rainfall in Southwest China. In this study, the heat source is found to be increased over the western part of the plateau while decreased over the eastern part of the plateau as the mountain uplifting, which is in agree with Chen et al. (2001). The thermodynamic effects of the plateau promote the ascending motion over Southwest China, affecting the amount of autumn rainfall there, correspondingly.

It should be noted that, as a peculiar climatic phenomenon, the autumn rainfall over Southwest China has numerous reasons for its formation and continued existence. In this study, we have only examined the effects of mountain uplift on this phenomenon from the perspective of atmospheric circulation and changes of the surface heat source. Further researches are needed to determine whether the dynamic effects or thermodynamic effects of plateau uplift are dominant in influencing the formation of the autumn rainfall. On the other hand, since the global mountain are changed uniformly in this study, it is hard to tell apart the specific effects of the Tibetan Plateau uplift. More experiments with individual mountain uplift are required to quantify the exact effects of plateau uplift on the autumn rainfall over Southwest China.

Acknowledgements The authors are grateful to Prof. Zhong Zhong in the PLA University of Science and Technology for his valuable advice. We acknowledge Prof. Akio Kitoh for kindly providing the model outputs. This research was jointly supported by the National Key Research and Development Program of China (grant no. 2016YFA0600401), the National Natural Science Foundation of China (grant nos. 41671197, 41971108, and 41631175), Open Funds of State Key Laboratory of Loess and Quaternary Geology, Institute of Earth Environment, CAS (SKLLQG1930, SKLLQG1820), and the Priority Academic Development Program of Jiangsu Higher Education Institutions (PAPD, grant no. 164320H116).

\section{REFERENCES}

Abe, M., A. Kitoh, and T. Yasunari, 2003: An Evolution of 
the Asian Summer Monsoon Associated with Mountain Uplift-Simulation with the MRI AtmosphereOcean Coupled GCM-. J. Meteorol. Soc. Jpn., 81, 909-933, doi: 10.2151/jmsj.81.909. [Link]

Abe, M., T. Yasunari, and A. Kitoh, 2005: Sensitivity of the central Asian climate to uplift of the Tibetan Plateau in the coupled climate model (MRI-CGCM1). The Island Arc, 14, 378-388, doi: 10.1111/j.14401738.2005.00493.x. [Link]

An, Z., J. E. Kutzbach, W. L. Prell, and S. C. Porter, 2001: Evolution of Asian monsoons and phased uplift of the Himalaya-Tibetan plateau since Late Miocene times. Nature, 411, 62-66, doi: 10.1038/35075035. [Link]

Bai, H. and W. Dong, 2004: Climate features and formation causes of autumn rain over Southwest China. Plateau Meteorology, 23, 884-889. (in Chinese)

Bao, Y., Abulimiti, F. Li, and X. Wang, 2003: Space-time distribution and physical mechanisms of autumn rains in west China in 2001. J. Appl. Meteor. Sci., 14, 215222. (in Chinese)

Cai, X., Z. Kang, R. Niu, and Y. Bao, 2012: Analysis of features and physical mechanisms of 2011 autumn rainfall in West China. Meteorological Monthly, 38, 828-833. (in Chinese)

Cai, X., L. Kang, X. Sun, Q. Li, and M. Mao, 2013: Study of circulation characteristics in autumn flood period over Weihe and Hanjiang River basins and the causes of flood by the heavy rains in 2011. Torrential Rain and Disasters, 32, 120-125. (in Chinese)

Chen, L., J. Liu, X. Zhou, and P. Wang, 1999: Impact of uplift of Qinghai-Xizang Plateau and change of landocean distribution on climate over Asia. Quaternary Sciences, 4, 314-329. (in Chinese)

Chen, M., P. Xie, J. E. Janowiak, and P. A. Arkin, 2002: Global land precipitation: A 50-yr monthly analysis based on gauge observations. J. Hydrometeor., 3, 249266, doi: 10.1175/1525-7541(2002)003<0249:GLPA $\mathrm{YM}>2.0 . \mathrm{CO} ; 2$. [Link $]$

Chen, M., T. Niu, S. Guo, J. Liu, and X. Ding, 2014: Circulation characteristics of continuous disastrous rainstorms and terrain forcing effect on September 2011 in west China. Journal of Meteorology and Environment, 30, 1-8. (in Chinese)

Chen, Z., F. Liu, P. Zhao, and Z. Ma, 2001: Relationship between the Surface Heating Fields over Qinghai-Xizang Plateau and Precipitation of Southwest China in Autumn. Plateau Meteorology, 20, 94-99. (in Chinese)

Fan, G. and G. Cheng, 2003: Influence of the QinghaiXizang Plateau uplifting on precipitation change in Northwest China. Plateau Meteorology, 22, 67-74. (in Chinese)

Feng, L. and Q. Guo, 1983: The fluctuation of autumn rain in South-West China. Geographical Research, 2, 7484. (in Chinese)
Gao, Y., 1958: On the high autumn clear weather in China. Acta Meteorologica Sinica, 29, 83-92, doi: 10.11676/ qxxb1958.010. (in Chinese) [Link]

Gao, Y. and Q. Guo, 1958: On the autumn raining area in China. Acta Meteorologica Sinica, 29, i264-i273. (in Chinese)

He, M., 1984: Distribution and long-term forecast of Chinese autumn rainfalls. Meteorological Monthly, 10, 10-13. (in Chinese)

Jiang, D., Z. Ding, H. Drange, and Y. Gao, 2008: Sensitivity of East Asian climate to the progressive uplift and expansion of the Tibetan Plateau under the mid-Pliocene boundary conditions. Adv. Atmos. Sci., 25, 709-722, doi: 10.1007/s00376-008-0709-x. [Link]

Jiang, Z., Z. Ma, J. Liu, and Q. Li, 2014: Improved index and climatological characteristics of the autumn rain in western China. Chinese Journal of Atmospheric Sciences, 38, 32-44. (in Chinese)

Kalnay, E., M. Kanamitsu, R. Kistler, W. Collins, D. Deaven, L. Gandin, M. Iredell, S. Saha, G. White, J. Woollen Y. Zhu, M. Chelliah, W. Ebisuzaki, W. Higgins, J. Janowiak, K. C. Mo, C. Ropelewski, J. Wang, A. Leetmaa, R. Reynolds, R. Jenne, and D. Joseph, 1996: The NCEP/NCAR 40-year reanalysis project. Bull. Amer. Meteorol.Soc., 77, 437-472, doi: 10.1175/ 1520-0477(1996)077<0437:TNYRP>2.0.CO;2. [Link]

Kitoh, A., 2004: Effects of Mountain Uplift on East Asian Summer Climate Investigated by a Coupled Atmosphere-Ocean GCM. J. Clim., 17, 783-802, doi: 10.1175/1520-0442(2004)017<0783:EOMUOE $>2.0$. CO;2. [Link]

Kitoh, A., 2007: ENSO modulation by mountain uplift. Clim. Dyn., 28, 781-796, doi: 10.1007/s00382-0060209-6. [Link]

Kitoh, A., T. Motoi, and O. Arakawa, 2010: Climate modelling study on mountain uplift and Asian monsoon evolution. Geol.Soc. Lond.Spec. Publ., 342, 293-301, doi: 10.1144/sp342.17. [Link]

Kutzbach, J. E., W. L. Prell, and W. F. Ruddiman, 1993: Sensitivity of Eurasian climate to surface uplift of the Tibetan Plateau. J. Geol., 101, 177-190, doi: 10.1086/648215. [Link]

Lee, J.-Y., B. Wang, K.-H. Seo, K.-J. Ha, A. Kitoh, and J. Liu, 2015: Effects of mountain uplift on global monsoon precipitation. Asia-Pac. J. Atmos. Sci., 51, 275290, doi: 10.1007/s13143-015-0077-2. [Link]

Li, G., H. Lu, C. Huang, Y. Fan, and B. Zhang, 2016: A climatology of the surface heat source on the Tibetan Plateau in summer and its impacts on the formation of the Tibetan Plateau vortex. Chinese Journal of Atmospheric Sciences, 40, 131-141.

Li, J. and X. Fang, 1999: Uplift of the Tibetan Plateau and environmental changes. Chin. Sci. Bull., 44, 2117 2124, doi: 10.1007/BF03182692. [Link] 
Li, Y., W. Li, W. Ai, and Y. Chen, 2012: Analysis of autumn rainfall characteristics and its causes in West China in 2011. Advances in Meteorological Science and Technology, 2, 27-33.

Liang, X., Y. Liu, and G. Wu, 2005: The impact of QinghaiXizang plateau uplift on Asian general circulation in spring and summer. Plateau Meteorology, 24, 837845. (in Chinese)

Liu, J., L. Mao, T. Niu, M. Chen, H. Liu, and J. Wang, 2013: Numerical simulation study on the impact of topographic forcing on the disaster rainstorm in west China in September 2011. Meteorological Monthly, 39, 975987. (in Chinese)

Liu, J., Z. Ma, S. Yang, and J. Xu, 2015a: Relationship between Indian Ocean dipole and autumn rainfall in West China. Plateau Meteorology, 34, 950-962. (in Chinese)

Liu, X., 1999: Influences of Qinghai-Xizang (Tibet) Plateau uplift on the atmospheric circulation, global climate and environment changes. Plateau Meteorology, 18, 321-332. (in Chinese)

Liu, X. and Z.-Y. Yin, 2002: Sensitivity of East Asian monsoon climate to the uplift of the Tibetan Plateau. Palaeogeogr. Palaeoclimatol. Palaeoecol., 183, 223-245, doi: 10.1016/s0031-0182(01)00488-6. [Link]

Liu, X. and H. Yuan, 2006a: Effects of ENSO on the relationship between IOD and autumn rainfall in China. Journal of Nanjing Institute of Meteorology, 29, 762768. (in Chinese)

Liu, X. and H. Yuan, 2006b: Relationship between the Indian Ocean Dipole and Autumn Rainfall in China. Journal of Nanjing Institute of Meteorology, 29, 644-649. (in Chinese)

Liu, X., L. Li, and Z. An, 2001: Tibetan Plateau uplift and drying in Eurasian interior and northern Africa. Quaternary Sciences, 21, 114-122. (in Chinese)

Liu, X., H. Sun, Y. Miao, B. Dong, and Z.-Y. Yin, 2015b: Impacts of uplift of northern Tibetan Plateau and formation of Asian inland deserts on regional climate and environment. Quat. Sci.Rev., 116, 1-14, doi: 10.1016/j. quascirev.2015.03.010. [Link]

Liu, Y., B. Hoskins, and M. Blackburn, 2007: Impact of Tibetan orography and heating on the summer flow over Asia. J. Meteorol. Soc. Jpn., 85B, 1-19, doi: 10.2151/ jmsj.85b.1. [Link]

Liu, Y., L. Sun, C. Sun, Z. Wang, Y. Wang, and Y. Yuan, 2012: Analysis of anomalies of autumn rain in West China in 2011 and its possible mechanism. Meteorological Monthly, 38, 456-463. (in Chinese)

Luo, X., D. Li, and H. Wang, 2013: New evolution features of autumn rainfall in West China and its responses to atmospheric circulation. Plateau Meteorology, 32, 1019-1031. (in Chinese)

Ruddiman, W. F. and J. E. Kutzbach, 1991: Plateau Uplift and Climatic Change. Sci. Am., 264, 66-75, doi: 10.1038/scientificamerican0391-66. [Link]

Song, J.-H., H.-S. Kang, Y.-H. Byun, and S.-Y. Hong, 2010: Effects of the Tibetan Plateau on the Asian summer monsoon: A numerical case study using a regional climate model. Int. J. Climatol., 30, 743-759, doi: 10.1002/joc.1906. [Link]

Su, F., X. Duan, D. Chen, Z. Hao, and L. Cuo, 2013: Evaluation of the Global Climate Models in the CMIP5 over the Tibetan Plateau. J. Clim., 26, 3187-3208, doi: 10.1175/jcli-d-12-00321.1. [Link]

Sun, X., N. Wei, and K. Xiao, 2010: Variation characteristics of autumn precipitation in Shaanxi Province. Journal of Applied Meteorological Science, 21, 360-365. (in Chinese)

Sun, Z., X. Yang, and Z. Ma, 2013: Monitoring index and causes of autumn rains over Southwest China in recent 50 years. Meteorological Science and Technology, 41, 883-888. (in Chinese)

Tang, H., A. Micheels, J. T. Eronen, B. Ahrens, and M. Fortelius, 2013: Asynchronous responses of East Asian and Indian summer monsoons to mountain uplift shown by regional climate modelling experiments. Clim. Dyn., 40, 1531-1549, doi: 10.1007/s00382-0121603-x. [Link]

Tang, M., 1993: Some advances on the research of plateau monsoons (a review). Plateau Meteorology, 1. (in Chinese)

Wang, C., Z. Ma, P. Shao, J. Wang, and S. Fang, 2015a: Climate variation of Huaxi autumn rain and the impact factors influencing it. Arid Zone Research, 32, 11131121. (in Chinese)

Wang, C., Z. Ma, J. Wang, and J. Wang, 2015b: The characteristics of Huaxi autumn rain and its relationship with sea surface temperatures over the equatorial Pacific. Chinese Journal of Atmospheric Sciences, 39, 643652. (in Chinese)

Wang, H., Z. Wang, K. Wang, C. Peng, and Y. Zhu, 2018: Anomalous Circulation Characteristics of Autumn Rain and Its Cause over West China in 2017. Journal of Arid Meteorology, 36, 743-750. (in Chinese)

Wang, L., W. Chen, W. Zhou, and G. Huang, 2015c: Teleconnected influence of tropical Northwest Pacific sea surface temperature on interannual variability of autumn precipitation in Southwest China. Clim. Dyn., 45, 2527-2539, doi: 10.1007/s00382-015-2490-8. [Link]

Wang, S., S. Jiao, and H. Xin, 2013: Spatio-temporal characteristics of temperature and precipitation in Sichuan Province, Southwestern China, 1960-2009. Quat. Int., 286, 103-115, doi: 10.1016/j.quaint.2012.04.030. [Link]

Wang, T., G. Wu, and R. Wan, 2008: Influence of the mechanical and thermal forcing of Tibetan Plateau on the circulation of the Asian summer monsoon area. Plateau Meteorology, 27, 1-9. (in Chinese) 
Xu, G. and C. Lin, 1994: Survey on the causes and features of autumn rain in Western China. Scientia Meteorologica Sinica, 12, 149-154. (in Chinese)

Xu, J., C. Yan, Y. Zhong, J. Liu, and Z. Ma, 2017: Relationships between Euraisan teleconnection pattern in northern hemisphere autumn and autumn rainfall in west China. Meteorological Science and Technology, 45, 492-498, doi: 10.19517/j.1671-6345.20160491. (in Chinese) [Link]

Yang, J., Q. Liu, S.-P. Xie, Z. Liu, and L. Wu, 2007: Impact of the Indian Ocean SST basin mode on the Asian summer monsoon. Geophys. Res. Lett., 34, doi: 10.1029/2006g1028571. [Link]

Ye, D. and Y. Gao, 1979: Tibetan Plateau Meteorology, Science Press, 278 pp.

Yu, E., R. Zhang, D. Jiang, G. Ramstein, Z. Zhang, and J. Sun, 2018: High-resolution simulation of Asian monsoon response to regional uplift of the Tibetan Plateau with regional climate model nested with global climate model. Global Planet. Change, 169, 34-47, doi: 10.1016/j.gloplacha.2018.07.002. [Link]

Yu, Y., S. Wang, Z. Qian, M. Song, and A. Wang, 2013: Climatic linkages between SHWP position and EASM rainy belts and areas in east part of China in summer half year. Plateau Meteorology, 32, 1510-1525. (in Chinese)
Zhang, R., D. Jiang, X. Liu, and Z. Tian, 2012: Modeling the climate effects of different subregional uplifts within the Himalaya-Tibetan Plateau on Asian summer monsoon evolution. Chin. Sci. Bull., 57, 4617-4626, doi: 10.1007/s11434-012-5284-y. [Link]

Zhang, R., D. Jiang, Z. Zhang, and E. Yu, 2015: The impact of regional uplift of the Tibetan Plateau on the Asian monsoon climate. Palaeogeogr. Palaeoclimatol. Palaeoecol., 417, 137-150, doi: 10.1016/j.palaeo.2014.10.030. [Link]

Zhang, W., F.-F. Jin, J.-X. Zhao, L. Qi, and H.-L. Ren, 2013: The possible influence of a nonconventional El Niño on the severe autumn drought of 2009 in Southwest China. J. Clim., 26, 8392-8405, doi: 10.1175/jclid-12-00851.1. [Link]

Zhang, X., X. Zhang, H. Guan, and Z. Xie, 2011: The atmospheric circulation features of the heavy drought in southwest China in autumn 2009. Tropical Geography, 31, 21-27. (in Chinese)

Zhang, Y. and Y. Qian, 1999: Numerical studies on the effects of the critical height of Qinghai Xizang Plateau uplift on the atmosphere. Acta Meteorologica Sinica, 57, 157-167.

Zhao, J., Z. Ma, and G. Fan, 2016: Impact of the MaddenJulian Oscillation on autumn rainfall in west China. Plateau Meteorology, 35, 1487-1497. 